\title{
STUDY ON HALF-WIDTH AND MAXIMUM X-RAY INTENSITY OF DIFFRACTION LINE OF COLD-ROLLED AUSTENITIC STAINLESS STEEL AS A FUNCTION OF ARIMUTH ANGLE $\psi$
}

\author{
Le Chi Cuong \\ University of Technical Education Ho Chi Minh City \\ (Received April 11 $1^{\text {th }}$,2011, Accepted September 21 $1^{\text {st }}$,2012)
}

\begin{abstract}
This research studies on the maximum $x$-ray counts and half-width of the $x$-ray diffraction line of textured austenitic stainless steel. The experimental stress-independent direction almost agrees with the theoretical value, determined from the Voigt, Reuss and Kroner models. The result of loading test for two perpendicular SUS316L austenitic stainless steel specimens shows that the broadness and maximum intensity of diffraction line in the rolling direction respectively get the lowest and highest values around the stress-independent direction. In the traverse direction, the broadness and maximum intensity of diffraction line vary slightly as in the case of the isotropic materials.
\end{abstract}

Key words: X-ray Diffraction; Residual Stress; Textured Material; Stress Constant, Half-width.

\section{INTRODUCTION}

The broadness of an x-ray diffraction line, represented by the half-width (the width at half of maximum x-ray counts), is an important parameter that characterizes the material properties, such as fatigue level, alloying level, plastic deformation, hardness, dislocation density, etc. For the isotropic materials, the half-width is constant for all the $\psi$ angles because the mechanical characteristics are equal for all diffraction directions. For the textured material, however, the half-width may have different behaviors due to its anisotropy. Therefore, in studying the characteristic of textured materials, the half-widths for various $\psi$ angles other than $\psi=0^{\circ}$ should also be investigated.
On the other hand, Vietnam is in process of investing a nuclear power plant and stainless steel is a common material used. This research will investigate the change of half-width and the maximum $\mathrm{x}$-ray counts with $\psi$ angles for cold-rolled austenitic stainless steel SUS316L, which is used for many components such as reactor shroud [1]. The theoretical value of minimum of half-width is also computed and compared to the experimental result.

\section{HALF-WIDTH OF DIFFRACTION LINE FOR TEXTURED SPECIMEN DUE TO PLASTIC DEFORMATION}

\subsection{Strain-Stress relation for anisotropic materials}

Let us consider the coordinate system on the surface of a rolled specimen. The $x, y$ and $z$ axes are parallel to the rolling direction (RD), 
traverse direction (TD) and normal directions (ND). OP is the measurement direction and makes an azimuth $(\varphi, \psi)$ to the axes. The strain $\varepsilon_{i j}$ in the $i j$ direction ( $i, j=1$ to 3 ) is determined from the generalized Hooke's law as [2]

$$
\varepsilon_{i j}=\frac{1}{2} s_{2}^{(h k l)} \sigma_{i j}-\delta_{i j} s_{1}^{(h k l)} \sigma_{i j}
$$

where $s_{1}^{(h k l)}$ and $\frac{1}{2} s_{2}^{(h k l)}$ are elastic compliances of anisotropic material, depending on the diffraction plane $(h k l) ; \delta_{i j}$ is Kronecker's delta, $\delta_{i j}=1$ if $i=j$ and $\delta_{i j}=0$ if $i \neq j$. If we let the indices 1,2,3 in Eq. (1) be the axes $x, y$ and $z$ in Fig. 1, then the strain $\varepsilon$ measured in the OP direction is[3]

$$
\begin{aligned}
\mathcal{E}= & \frac{1}{2} s_{2}^{(h k l)}\left(\sigma_{x} \cos ^{2} \varphi \sin ^{2} \psi+\sigma_{y} \sin ^{2} \varphi \sin ^{2} \psi+\sigma_{z} \cos ^{2} \psi\right. \\
& \left.+\sigma_{x y} \sin 2 \varphi \sin ^{2} \psi+\sigma_{x z} \cos \varphi \sin 2 \psi+\sigma_{y z} \sin \varphi \sin 2 \psi\right) \\
& +s_{1}^{(h k l)}\left(\sigma_{x}+\sigma_{y}+\sigma_{z}\right)
\end{aligned}
$$

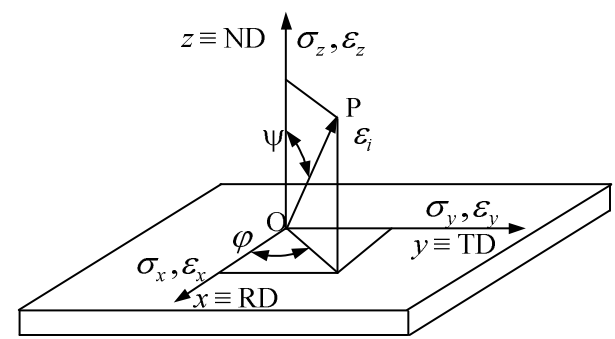

Fig. 1. Coordinate system and stress in the surface of a rolled specimen.

In the case of stress measurement in the $x$ direction $(\varphi=0)$ in the plane stress state, we omit the components in the $z$ direction and Eq.

(2) becomes:

$$
\varepsilon=\left(\frac{1}{2} s_{2}^{(h k l)} \sin ^{2} \psi+s_{1}^{(h k l)}\right) \sigma_{x}+s_{1}^{(h k l)} \sigma_{y}
$$

\subsection{Relation between half-width and residual strain of textured specimen due to plastic deformation}

The broadness (half-width) of an X-ray diffraction line can characterize the material properties. It depends on many factors such as heat treatment, alloying level, grain size, plastic deformation from machining or rolling process, and etc. In this study, the half-width is investigated as a function of azimuth angle $\psi$, which is the most important parameter in the anisotropic material. The considered specimens were supposed to be homogeneous, thus no gradient in stress, chemical composition or change in grain size and mechanical properties in the irradiated area. In that case, the halfwidth of an x-ray diffraction lines has relation to the spread of lattice spacing due to the plastic deformation. Since the residual stress has relation to the residual strain due to deformation, the spread of the half-width in the $\mathrm{RD}$ in this study is investigated in relation to the plastic deformation in the rolling process. The half-width is defined as $B=B_{\text {min }}+\Delta B$ (4)

where $B_{\min }$ is the minimum half-width of material without deformation and $\Delta B$ is the spread of half-width due to the deformation process. If we assumed that $\Delta B$ depends on the residual strain of material after deformation, we have

$$
B=B_{\min }+C\left(\frac{1}{2} s_{2}^{(h k l)} \sin ^{2} \psi+s_{1}^{(h k l)}\right)
$$

where $C$ is a constant. From Eq. (5), the halfwidth obtains the minimum value at the stress-

\section{Trang 82}


independent direction, which is determined as [4]

$$
\sin ^{2} \psi=-\frac{s_{1}^{(h k l)}}{0.5 s_{2}^{(h k l)}}
$$

For the isotropic materials, the elastic constants can be determined theoretically from the compliances of single crystal as $S_{11}=9.84$ $\mathrm{TPa}^{-1}, S_{12}=-3.86 \mathrm{TPa}^{-1}$ and $S_{44}=8.40 \mathrm{TPa}^{-1}$ using the Voigt, Reuß and Kroner models $[5,6,7]$. For the Voigt model, the strain is supposed to be constant for all constituent grains. The elastic constants in the Voigt model are given as:

$$
\begin{aligned}
s_{1} & =\frac{2 S_{0}\left(S_{11}+2 S_{12}\right)+5 S_{12} S_{44}}{6 S_{0}+5 S_{44}}, \\
\frac{1}{2} s_{2} & =\frac{5\left(S_{11}-S_{12}\right) S_{44}}{6 S_{0}+5 S_{44}}
\end{aligned}
$$

where $S_{0}=S_{11}-S_{12}-0.5 S_{44}$. The Reuß model assumed that the stress is constant for all the grains, giving the elastic constants as:

$$
s_{1}=S_{12}+S_{0} \Gamma, \frac{1}{2} s_{2}=S_{11}-S_{12}-3 S_{0} \Gamma
$$

Where $3 \Gamma$ is orientation parameter. For cubic structure, $\Gamma$ is given as:

$$
\Gamma=\frac{h^{2} k^{2}+k^{2} l^{2}+h^{2} l^{2}}{\left(h^{2}+k^{2}+l^{2}\right)^{2}}
$$

For diffraction plane (220) of austenite stainless steel SUS316L, 3Г $=0.75$.

In the Kroner model, the boundary conditions for stress and grain boundary displacement are satisfied. To simplify the calculation, the Kroner model is the combination of the Voigt and Reuß models as [11]

$$
s^{K}=0.583 s^{V}+0.417 s^{R}
$$

where $s^{K}, s^{V}$ and $s^{R}$ are the elastic compliances, determined from the Kroner, Voigt and Reuß models, respectively $[6,8,9,10]$. Since the Kroner model gives the closest elastic compliances to the measured value, the elastic constants calculated from the Kroner model are used.

The theoretical stress-independent direction for isotropic SUS316L stainless steel calculated from Eqs. (6) and (9) is

$$
\sin ^{2} \psi=0.23
$$

\section{EXPERIMENTAL \\ STRESS- INDEPENDENT DIRECTION}

In a previous study, the experimental stressindependent direction in the $\sin ^{2} \psi$ diagram is determined as

$$
u^{*}=-\frac{B_{x}}{A_{x}} ; p^{*}=p_{0}+\frac{A_{x} B_{y}-B_{x} A_{y}}{A_{x}} \sigma_{0 y}
$$

where $p_{0}$ is the peak position of a stress-free specimen,

$$
\begin{gathered}
A_{x}=\sum a_{i} k_{x i}, \quad A_{y}=\sum a_{i} k_{y i} \\
B_{x}=\sum b_{i} k_{x i}, \quad B_{y}=\sum b_{i} k_{y i} \\
a_{i}=\frac{n u_{i}-\sum u_{i}}{n \sum u_{i}^{2}-\left(\sum u_{i}\right)^{2}} b_{i}=\frac{u_{i}^{2}-u_{i} \sum u_{i}}{n \sum u_{i}^{2}-\left(\sum u_{i}\right)^{2}} \\
u_{i}=\sin ^{2} \psi \\
k_{x i}=\frac{\partial p_{i}}{\partial \sigma_{a x}}, k_{y i}=\frac{\partial p_{i}}{\partial \sigma_{a y}}
\end{gathered}
$$

$\sigma_{\mathrm{a} x} \sigma_{\mathrm{a} y}$ are the applied stresses along the $\mathrm{x}$ and y axises.

$\sigma_{0 y}$ is the residual stress along the $y$ directions;

$$
\sigma_{0 y}=-\frac{B_{x} M-A_{x}\left(N-p_{0}\right)}{A_{x} B_{y}-A_{y} B_{x}}
$$


$M$ and $N$ are the slop and intercept of the straight line fitted to the peak positions $p_{i}$ in the $\sin ^{2} \psi$ diagram:

$$
\begin{aligned}
& M=\sum a_{i} p_{i} \\
& N=\sum b_{i} p_{i}
\end{aligned}
$$

Substituting Eq. (16) into Eq. (11) and simplifying, we have the experimental stressindependent direction given by

$$
u^{*}=-\frac{B_{x}}{A_{x}} ; p^{*}=2 p_{0}+\frac{B_{x}}{A_{x}} M-N
$$

\section{EXPERIMENTAL PROCEDURE}

Two specimens A and B with the sizes of $3.9 \times 22 \times 100 \mathrm{~mm}$, having the longitudinal direction parallel to the $\mathrm{RD}$ and $\mathrm{TD}$, respectively, were prepared from cold-rolled austenitic stainless steel JIS type SUS316L, as shown in Fig. 2. The chemical compositions of the specimens are shown in Table 1. The surfaces of the specimens were electrolytically polished to remove the surface layer by about $70 \mu \mathrm{m}$. The conditions for the X-ray stress measurement are given in Table 2. The peak position of a stress-free specimen was determined by using SUS316L powder as $p_{0}$ $=160.280^{\circ}$. The fixed $\psi \psi$ method using the isoinclination method was used. The X-ray counts are corrected for the Lorentz-polarization and absorption factors [13]

Various stresses were applied to the longitudinal direction of the specimens using a four-point bending device. The applied stresses were measured mechanically using a strain gauge attached to the surfaces of the specimens. The peak positions of diffraction lines were measured in the RD for both specimens.

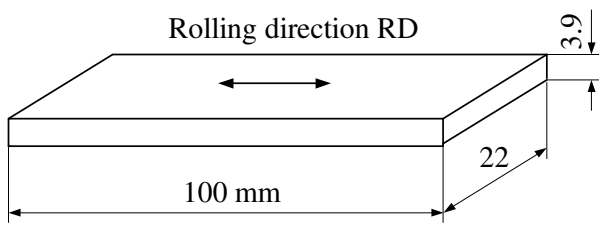

Specimen A

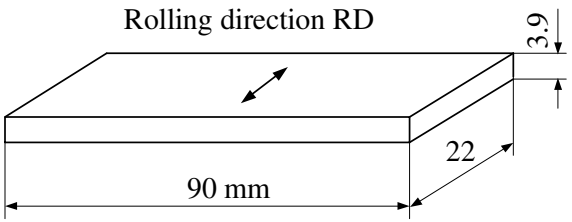

Specimen B

Fig. 2 Specimens.

Table 1. Chemical compositions of SUS316L specimens (wt. \%)

\section{Trang 84}




\begin{tabular}{llllllll}
\hline $\mathrm{C}$ & $\mathrm{Si}$ & $\mathrm{Mn}$ & $\mathrm{P}$ & $\mathrm{S}$ & $\mathrm{Ni}$ & $\mathrm{Cr}$ & $\mathrm{Mo}$ \\
0.012 & 0.66 & 1.17 & 0.028 & 0.002 & 12.1 & 17.2 & 2.1
\end{tabular}

Table 2. Experimental conditions for X-ray stress measurement

\begin{tabular}{l|l}
\hline Characteristic X-rays & $\mathrm{VK} \alpha$ \\
Diffraction plane & $(220)$ \\
Filter & $\mathrm{Ti}$ foil \\
Divergent angle of collimator & $1^{\circ}$ \\
Tube voltage & $30 \mathrm{kV}$ \\
Tube current & $10 \mathrm{~mA}$ \\
Irradiated area & $5 \times 10 \mathrm{~mm}^{2}$ \\
Preset time & $5 \mathrm{~s}$ \\
Step size & $0.15^{\circ}$ \\
\hline
\end{tabular}

\section{RESULTS AND DISCUSSION}

Figure 3 shows the variation of the maximum X-ray counts of the diffraction lines $y_{\max }$ in the $\mathrm{RD}$ and TD with the $\psi$ angles for specimen A. Generally, for the isotropic materials having no texture, the maximum X-ray counts decrease slowly with increasing $\psi$ angle because of the X-rays absorption

However, for the SUS316L specimens, $y_{\max }$ in the RD varies greatly with $\psi$ angles and obtains the maximum at around $\psi=30^{\circ}\left(\sin ^{2} \psi\right.$ $=0.25)$, showing that the specimens have very strong texture. Figures 4 and 5 respectively show the $\sin ^{2} \psi$ diagrams for the specimens $\mathrm{A}$ and $\mathrm{B}$ with various applied stresses $\sigma_{a x}$ and $\sigma_{a y}$. The peak positions in the $\sin ^{2} \psi$ diagrams for both specimens oscillate due to the strong texture. In Fig. 4, the straight lines fitted to the peak positions using the least square method for the specimen A intersect at a point having the coordinates determined from Eq. (19) as $\sin ^{2} \psi^{*}=0.26$ and $p^{*}=160.466^{\circ}$. This is the stress- independent direction, which almost agrees to the direction where the maximum $\mathrm{x}$ ray intensity obtains the highest value in Fig. 2. For specimen B in Fig. 5, the parallel lines determined from the peak positions by the least-square method show that the applied stresses in the $y$ direction have little influence on the slope of the straight lines in the $\sin ^{2} \psi$ diagram in the $x$ direction. 


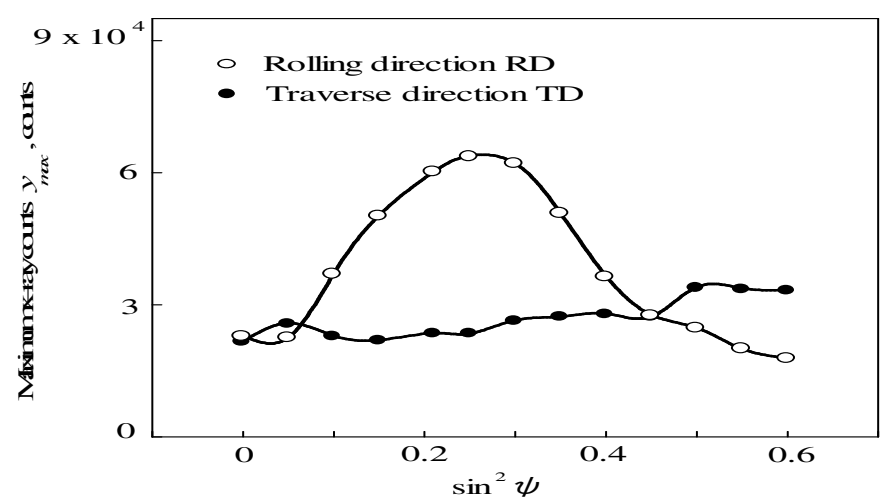

Fig. 3. Variation of maximum $X$-ray counts versus $\sin ^{2} \psi$ of specimen A.

Figure 6 shows the variation of the slope $M$ of the straight lines in the $\sin ^{2} \psi$ diagrams in Figs. 4 and 5 as a function of the applied stresses $\sigma_{a x}$ and $\sigma_{a y}$ for specimens $\mathrm{A}$ and $\mathrm{B}$. The slope $M$ for specimen A varies linearly with the applied stresses. For the specimen B, on the other hand, the $M-\sigma_{a y}$ diagram, are distributed around a horizontal line, showing that the applied stress has no influence on the stress in the direction $x$. The coefficients $A_{x}$ and $A_{y}$ in Eq. (12) are determined from the slopes in the $M-\sigma_{a}$ diagram in Fig.6.

Figure 7 shows the variation of the intercept $N$ of the straight lines in the $\sin ^{2} \psi$ diagrams in Figs. 4 and 5 with the applied stresses $\sigma_{a x}$ and $\sigma_{a y}$ of specimens $\mathrm{A}$ and $\mathrm{B}$, respectively. The intercept $N$, similarly to the slope $M$, varies linearly with the applied stresses $\sigma_{a x}$ and $\sigma_{a y}$. The coefficients $B_{x}$ and $B_{y}$ in Eq. (13) are determined from slopes of the $N-\sigma_{a}$ diagram in Fig. 7 for both specimens $\mathrm{A}$ and $\mathrm{B}$, respectively.

Table 3 shows the values of the coefficients $A_{x}, B_{x}, A_{y}$ and $B_{y}$ determined from Eqs. (12) and
(13) by applying stresses to the specimens A and $\mathrm{B}$, respectively.

Table 3. Coefficients $A_{x}, B_{x}, A_{y}$ and $B_{y}\left(10^{-4}\right.$

\begin{tabular}{cc}
\multicolumn{2}{c}{$\mathrm{deg} / \mathrm{MPa})$} \\
\hline$A_{x}$ & -33.50 \\
$B_{x}$ & 8.85 \\
$A_{y}$ & 0.09 \\
$B_{y}$ & 7.10
\end{tabular}

Figure 8 shows the variation of the halfwidth $B$ of diffraction line of the specimens A and $\mathrm{B}$ in the $\mathrm{RD}$ and $\mathrm{TD}$ with $\sin ^{2} \psi$ value without applied stress. For both specimens, the half-widths oscillate with $\sin ^{2} \psi$ corresponding with the oscillation of the peak positions in Figs. 6 and 7, showing that together with the change of the lattice distance due to the rolling process, the half-width of x-ray diffraction line varies. However, since the deformation in the $\mathrm{RD}$ is much larger than in the TD, the halfwidths measured in the RD are generally larger than those measured in the TD.

\section{Trang 86}




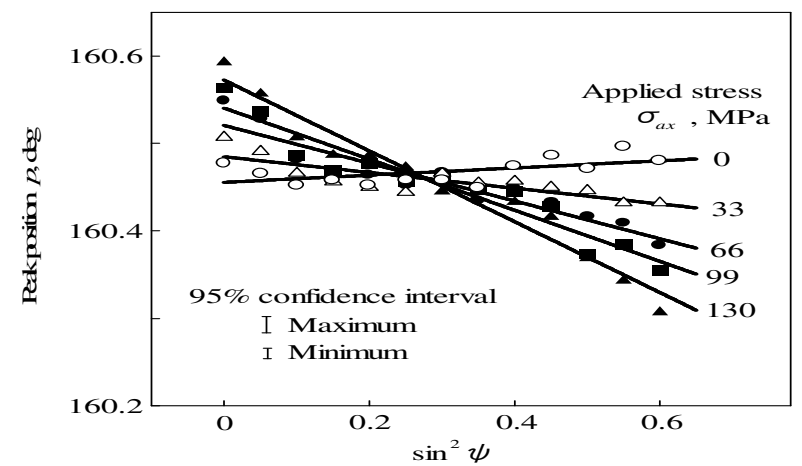

Fig. 4. $\operatorname{Sin}^{2} \psi$ diagram of specimen A.

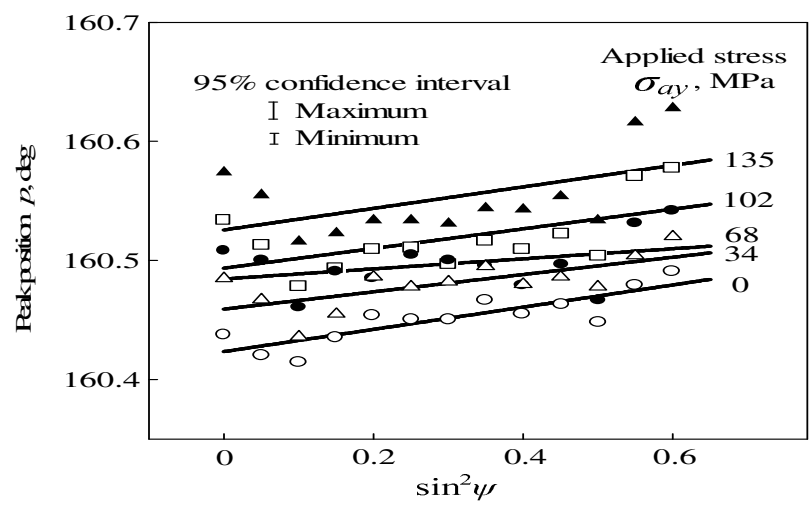

Fig. 5. $\operatorname{Sin}^{2} y$ diagram of specimen B.

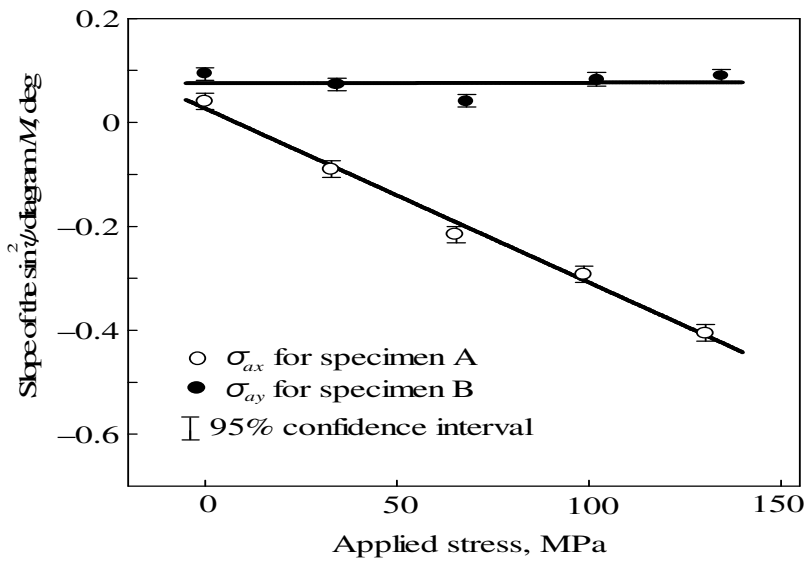

Fig. 6. Variation of the slope $M$ in the $\sin ^{2} \psi$ diagram with applied stresses. 
On the other hand, the half-width in the RD greatly varies with $\sin ^{2} \psi$ while in the $\mathrm{TD}$, the half-width oscillate smoothly in the horizontal direction. The half-widths in Fig. 8 in the RD and TD are fitted with a parabola. In the RD, the half-width obtains the minimum at $\sin ^{2} \psi$ of about 0.28 , which almost agrees with the stress- independent direction in Fig. 4, determined experimentally from Eqs. (19) and theoretically from Eq. (10) for isotropic materials. This value also approximately agrees with the value, where the maximum $x$-ray counts obtain the maximum value in Fig. 4, showing that the half-width and the maximum X-ray counts of textured materials respectively obtain the minima and maxima at around the stress- independent direction.

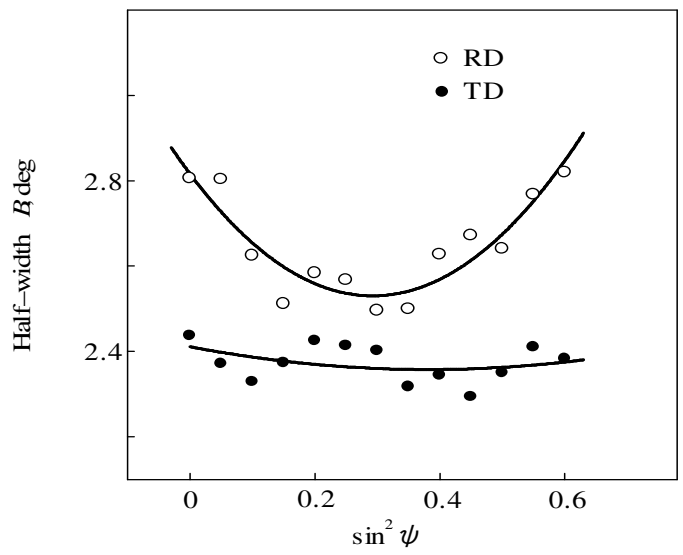

Fig. 8. Half-width of diffraction lines in RD and TD with $\sin ^{2} \psi$.

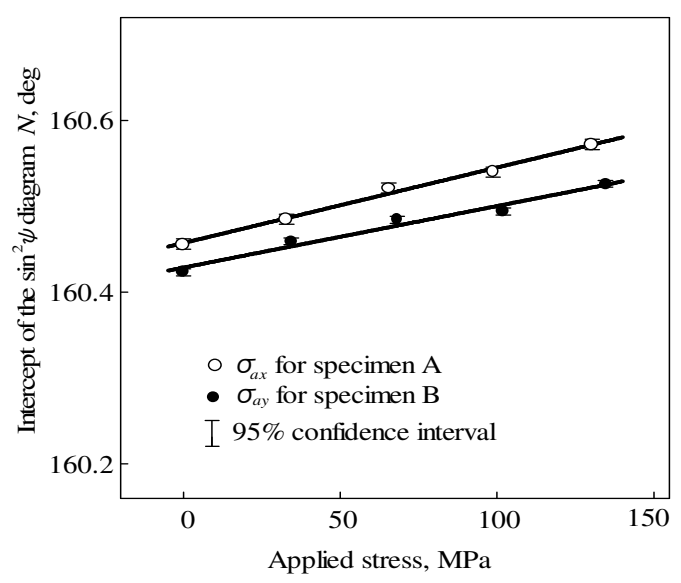

Fig. 7. Variation of intercept $N$ of the $\sin ^{2} \psi$ diagram with applied stress.

\section{Trang 88}




\section{CONCLUSIONS}

In this paper, the experimentally determining stress-independent direction of anisotropic materials was given. This agreed to the theoretical value of the isotropic material determined from the Voigt, Reuss and Kroner models. The broadness and maximum intensity of diffraction line in the rolling direction respectively get the lowest and highest values around the stress-independent direction. In the traverse direction, the broadness and maximum intensity of diffraction line vary slightly as in the case of the isotropic materials.

\title{
KHẢO SÁT BỂ RộNG TRUNG BÌNH VÀ CƯờnG Độ NHIẼU Xạ CAO NHÁT CỦA ĐƯờNG NHIẼ̃U Xạ CỦA THÉP KHÔNG RỈ CÁN NGUỘI AUSTENITIC THEO GÓC PHƯONG V!̣ $\Psi$
}

\author{
Lê Chí Cương \\ Trường Đại học Sư phạm Kỹ thuật Tp.HCM
}

TÓM TÁT: Bài nghiên cưu đã khảo sát sự thay đổi bề rộng trung bình và cuờng độ nhiễu xa cực đại của đường nhiễu xa X quang của thép không rỉ austenite có tổ chức tex tua. Điểm không phu thuộc ứng suất xác định bằng thực nghiệm được so sánh với giá trị lý thuyết, tính toán bằng các giả thiết Voigt, Reuss và Kroner. Kết quả thử nghiệm đo ưng suất có đặt tải trọng cho hai mẫu thủ thép không rỉ austenite SUS316L cho thấy tại điểm không phu thuộc ưng suất, bề rộng trung bình theo phuơng cán có giá trị nhỏ nhất, đồng thời cuờng độ lớn nhất của đường nhiễu xạ đạt gía trị cục đại. Theo phuơng ngang, bề rộng trung bình của đùng nhiễu xa cũng nhu cuờng độ nhiễu xa lớn nhất thay đổi không đáng kể, tuoong tư như vật liệu đẳng huớng.

Tù khóa: Nhiễu xạ tia X; íng suất du; Vật liệu tex-tua; Hằng số ưng suất.

\section{REFERENCES}

[1]. Shunsuke UCHIDA, Stress Corrosion Cracking of Stainless Steel, Nondestructive Testing and Evaluation, Vol. 52, No. 5, (2003).

[2]. Lu, J., James, M. and Roy. G., Handbook of Measurement of Residual Stress, Society for Experimental Mechanics, The Fairmont Press Inc., 225, (1996).
[3]. Noyan, I.C. and Cohen, J.B., Residual Stress, Sringer-Verlag, 145, (1987).

[4]. Hauk, V., Structural and Residual Stress Analysis by Nondestructive Methods, Evaluation- Application-Assessment", Elsevier, Amsterdam, 40, (1997).

[5]. Hellwege, K.H., Numerical Data and Functional Relationships in Science and Technology, Group III: Crystal and Solid 
State Physics, Vol. 1: Elastic, Piezoelectric and Electrooptic Constants of Crystal, Springer-Verlag, Berlin, 1-7, (1966).

[6]. Bollenrath, V.F., Hauk, V. and Muller, H., Zur Berechnung der vielkristallinen Elastizitatskonstanten aus den Werten der Einkristalle, Z.Metallkde, 58, 76-82, (1967).

[7]. Ch. Genzel, X-Ray Stress Analysis In Presence Of Gradients And Texture, Advances in X-ray Analysis, Vol. 44, 247, (2001).

[8]. Wenk, H.R. and Houtte, P. Van, Texture and Anisotropy, Report on Progress in Physics, 67, 1367-1428, (2004).

[9]. Cheng, P. and Yao, Y. L., The Influence of Sheet Metal Anisotropy on Laser Forming Process, Transactions of the ASME, Vol. 127, 572-582, (2005).

[10].C. O. Osueke, P. Uzendu and I.O.
Nwabueze, Study of Stress-Strain and Anisotropic Behavior of Sheet Metal for Deep Drawing Processes, International Journal of Advanced Engineering Sciences and Technologies, Vol. 9, Issue No. 2, $280-288,(2011)$.

[11]. The Society of Material Science, Japan: X-ray Stress Measurement Methods, Yokendo, Tokyo, 81, (in Japanese), 1981.

[12].Cuong L. C., PhD. Thesis, Nagaoka University of Technology, (2005).

[13].Cuong, L.C. and Kurita, M., Absorption Factor and Influence of LPA Factor on Stress and Diffraction Line Width in $X$ Ray Stress Measurement with and without Restriction of X-Ray Diffraction Area, the Japanese Society for Experimental Mechanics, Vol. 4, No. 1, 37-44, (2004).

\section{Trang 90}

